\title{
Social Support and Depressive Symptoms Among Displaced Older Adults Following the 1999 Taiwan Earthquake
}

\author{
Chie Watanabe, ${ }^{1,4}$ Junko Okumura, ${ }^{2}$ Tai-Yuan Chiu, ${ }^{3}$ and Susumu Wakai ${ }^{2}$
}

\begin{abstract}
This longitudinal study examines changes in depressive symptoms among displaced older Taiwanese adults $(N=54, M=68$ years), and the impact of various social supports for them at between 6 and 12 months after an earthquake. The average depression score between 6 and 12 months following the earthquake was unchanged and kept high score. Child and extended family support levels related to depressive symptoms after 6 months. In contrast, after 12 months, significant factors associated with a lessening of the depressive symptoms were social support from the extended family and neighbors, and social participation. Intervention to promote increased social networks and social participation, within their new environment in a temporary community, is highly recommended for older adults.
\end{abstract}

KEY WORDS: older adults; displaced people; depression; natural disaster; Taiwan.

The Taiwan Chi-Chi earthquake magnitude 7.3 on Richter Scale struck central Taiwan at 1:47 a.m. on September 21, 1999. The death toll was 2,471 with 11,305 injured. According to national statistics, 4,700 families were living in temporary housing 5 months after the earthquake (Department of Accounting and Statistics, 2000).

It is often reported that older adults are particularly vulnerable to the negative psychological effects of disaster (Phifer \& Norris, 1989; Raphael, 1986) and that relocated people are more distressed than other survivors (Bland et al., 1997; Gleser, Green, \& Winget, 1981). Such findings suggest that older relocatees may be an especially important population for research and intervention.

\footnotetext{
${ }^{1}$ Department of Social Gerontology, Graduate School of Medicine, The University of Tokyo, Tokyo, Japan.

${ }^{2}$ Department of International Community Health, Graduate School of Medicine, The University of Tokyo, Tokyo, Japan.

${ }^{3}$ Department of Family Medicine, College of Medicine and Hospital, National Taiwan University, Taiwan.

${ }^{4}$ To whom correspondence should be addressed at Department of Social Gerontology, Graduate School of Medicine, The University of Tokyo, 7-3-1 Hongo, Bunkyo-ku, Tokyo 113-0033, Japan; e-mail: fwnc9944@ mb.infoweb.ne.jp.
}

After the Hanshin-Awaji Earthquake in Japan, about $40 \%$ of older families who were accommodated in temporary housing found that reconstructing new relationships was difficult for them after the loss of lifelong communities (Tanida, 1996). Kaniasty and Norris (1993) reported that the direct impact of disaster, that of personal loss, had an intense but usually a short-term effect on older adults' depressive symptoms. In contrast, community destruction and loss of social support systems associated with the disaster created long-term psychological distress.

Several studies have found that social support lessens the impact of traumatic stress (Bolin \& Klenow, 1983; Tyler \& Hoyt, 2000). However, to be used, the support must be of an appropriate form from an appropriate source (e.g., Cohen \& Mckay, 1984). According to Kaniasty and Norris's study on depression at recovery phase after disaster, only nonkin support and social embeddedness were significantly related to depression (Kaniasty \& Norris, 1993). The present study examined the impact of varied sources of postdisaster social support on depression, longitudinally, among displaced old adults in an Oriental society. 


\section{Method}

\section{Participants}

Ju-Shan town situated in Nan-Tou county (central Taiwan), was selected as the study site. The city was selected because it was severely damaged by the earthquake and the proportion of elderly population was relatively high compared with other areas. There was a $0.18 \%$ mortality rate attributed to the earthquake in this community (Department of Accounting and Statistics, 2000). For the following 2 months in Ju-Shan, 125 temporary houses were built for those who lost their homes following the earthquake. One year later, 312 displaced people were still living in them.

The participants were all individuals over 55 years old who had been evacuated and were living in temporary housing (displaced group). A comparison group of similarly-aged adults was randomly selected from the area adjacent to the temporary housing.

In April 2000, 6 months postearthquake; data were collected from 56 displaced older adults and 48 nondisplaced ones. The second phase of data collection was conducted during September and October, 12 months postearthquake. Because half of the original nondisplaced participants moved to live with their families or relatives before the initiation of phase 2, no follow-up was conducted of the comparison group. Of the displaced group, $54(96 \%)$ were successfully re-interviewed. Two participants had moved out of temporary housing. Mean age of the 54 participants was 68.1 years $(S D=9.5)$. Sixteen participants (29.6\%) were living alone. Their religion was either Buddhism (25.9\%) or traditional belief (Chinese folk-religion; $59.3 \%)$. In phase 2, $12(22.5 \%)$ of the 54 respondents, had started reconstructing their houses, and $9(16.7 \%)$ decided to move to another place to live with their children. Thirty-three respondents $(61.1 \%)$ did not have firm plans for their future housing. Before interviewing them, we asked family members if participants had any symptoms like dementia or any psychiatric disease history before the earthquake. If the participants lived alone, we asked their primary health nurse working in their community. No cases were excluded from this study on the basis of previous disorders.

\section{Procedure}

Questionnaires were developed in Mandarin Chinese. Face-to-face interviews following a structured questionnaire were carried out in participants' homes. The interviews were done by one of the authors and one local interviewer who was trained a day prior to the survey.

\section{Instruments}

\section{Resource Loss}

The questionnaire included measures of personal loss (death or severe injury experienced by family or close friends), house loss (totally or partially), social activity loss (including working status), physical health impairment, and financial loss. These questions were answered in a form of "yes" or "no."

\section{Social Support}

Levels of social support were measured using the Social Support Scale (Noguchi, 1998) that has been used extensively to measure perceived social support among older people in Japan. The Cronbach's alpha of the original version was .89. The scale was translated from Japanese to Chinese and confirmed by back translation. The scale has 12 items and three dimensions: emotional, instrumental, and negative supports. Five sources of support were assessed: spouse, child living with participant (coresident child), child living separately from participant (nonresident child), extended family, and neighborhoods. The total support scores, which included emotional and instrumental support, were analyzed as an independent variable. The social support score ranged from 0 to 8 points.

Social participation was examined by seeking responses regarding working status (whether working or not and type of job), the number of social activities participated in, and their frequency (number of times of participating in a week).

\section{Depressive Symptoms}

Depressive symptoms were assessed by the SelfRating Depression Scale (SDS) developed by Zung (1965). The SDS has 20 items to quantify the severity of current depressive symptoms. The Chinese version has been used in several studies, and its validity established (Leung, Lue, Lee, \& Tang, 1998). Based on the pretest results, we had to delete two items from the original SDS: (1) loss of sexual desire and (2) suicidal rumination. When we conducted pretests on 20 participants, most of them strongly objected to the item on loss of sexual desire, in spite of assurances that their privacy was protected. As Leung et al. (1998) 
Table 1. Depressive Score and Social Support, Social Participation by Phase $(N=54)$

\begin{tabular}{|c|c|c|c|c|}
\hline & \multicolumn{2}{|c|}{ Phase $1^{a}$} & \multicolumn{2}{|c|}{ Phase $2^{a}$} \\
\hline & $M$ & $S D$ & $M$ & $S D$ \\
\hline Depressive score ${ }^{b}$ & 41.4 & 7.64 & 40.9 & 6.42 \\
\hline \multicolumn{5}{|l|}{ Social support } \\
\hline Spouse support ${ }^{c}$ & 2.26 & 3.21 & 2.37 & 3.39 \\
\hline Coresident child support ${ }^{c}$ & 2.69 & 3.50 & 2.41 & 3.46 \\
\hline Nonresident child support $^{c}$ & 3.89 & 3.26 & 4.39 & 3.21 \\
\hline Extend family support ${ }^{c}$ & 1.94 & 2.76 & 2.54 & 2.63 \\
\hline \multirow[t]{2}{*}{ Neighbor support } & 1.50 & 1.97 & 3.44 & $2.06^{* * *}$ \\
\hline & $n$ & $\%$ & $n$ & $\%$ \\
\hline \multicolumn{5}{|l|}{ Social participation $^{d}$} \\
\hline Yes & 18 & 32.1 & 20 & 37.0 \\
\hline No & 38 & 67.9 & 34 & 63.0 \\
\hline
\end{tabular}

Note. Depressive score was tested by paired $t$ test and the social support scores were done by Wilcoxson signed rank (paired) test because of differences in their distribution.

${ }^{a}$ Phase $1: 6$ months after the earthquake; phase $2: 12$ months after the earthquake.

${ }^{b}$ Depressive score: modified SDS score.

'If there were no support providers, it was scored as " 0 ."

${ }^{d}$ If the respondent participated in any social activities or was working, it was defined as "yes."

$* * * p<.001$.

indicated, Chinese people, especially older adults, perceive sex-related issues as something shameful, and they are embarrassed by speaking about sex to others. Also, some respondents were very nervous and worried about being a burden for the family. Therefore, it was considered ethically unacceptable to ask, "I feel that others would be better off if I were dead." The coefficient alpha of the modified SDS Chinese version was .85 .

\section{Results}

\section{Depressive Symptoms and Social Support by Phase}

In phase 1, the data confirmed that the displaced group had significantly higher depressive symptoms than the nondisplaced group $(M=41.4, S D=7.64$ vs. $M=$ $35.5, S D=7.90), t(102)=3.8, p<.001$. The mean depressive scores of the displaced group at phases 1 and 2 were not significantly different from each other, $t(53)<$ 1. At phase 2, the mean score of social support by neighbors was significantly higher than at phase $1(Z=-4.25$, $p<.001)$, although other levels of social supports did not change (Table 1).

\section{Relation Between Conditions Affected by the Earthquake and Depressive Symptoms}

Of the resource loss variables, only personal loss was associated with a higher level of depressive symptoms and this was true only at phase $1, t(52)=-2.22$, $p<.05$.

\section{Relation Between Social Support and Depressive Symptoms by Phase}

Table 2 shows the correlations between the social support measures and depressive symptoms. Table 3 presents the results of the partial correlation analysis by phase. At phase 1, correlations were adjusted for age and personal loss. Family supports, received from child

Table 2. Zero Order Speaman's Rank Correlations Among Social Support and Depression Measures $(N=54)$

\begin{tabular}{|c|c|c|c|c|c|c|c|c|c|c|c|c|c|c|}
\hline \multirow[b]{2}{*}{ Variables } & \multicolumn{7}{|c|}{ Phase 1} & \multicolumn{7}{|c|}{ Phase 2} \\
\hline & 1 & 2 & 3 & 4 & 5 & 6 & 7 & 8 & 9 & 10 & 11 & 12 & 13 & 14 \\
\hline \multicolumn{15}{|l|}{ Phase 1} \\
\hline 1. Spouse support & 1.00 & -.10 & .10 & .21 & .00 & .11 & -.19 & $.75^{* *}$ & $-.36^{* *}$ & .26 & .21 & .00 & .05 & -.24 \\
\hline 2. Coresident child support & & 1.00 & .12 & .13 & .19 & -.06 & -.07 & -.13 & $.68^{* *}$ & .19 & .19 & .10 & -.12 & -.09 \\
\hline 3. Nonresident child support & & & 1.00 & -.01 & $.29 *$ & -.01 & $-.36^{* *}$ & -.06 & .15 & $.52^{* *}$ & .12 & .16 & -.02 & -.18 \\
\hline 4. Extended family support & & & & 1.00 & .04 & .12 & $-.31^{*}$ & .09 & .09 & .25 & $.51^{* *}$ & $.36^{* *}$ & .11 & $-.44^{* *}$ \\
\hline 5. Neighbor support & & & & & 1.00 & -.11 & -.03 & -.12 & .17 & .15 & .02 & -.07 & -.12 & .26 \\
\hline 6. Social participation & & & & & & 1.00 & -.09 & .16 & $-.33^{*}$ & .07 & $.28^{*}$ & .06 & $.92^{* *}$ & -.27 \\
\hline 7. Depressive score & & & & & & & 1.00 & .00 & -.04 & -.21 & -.21 & -.07 & -.05 & $.59^{* *}$ \\
\hline \multicolumn{15}{|l|}{ Phase 2} \\
\hline 8. Spouse support & & & & & & & & 1.00 & $-.37^{* *}$ & .08 & .09 & .08 & .10 & -.08 \\
\hline 9. Coresident child support & & & & & & & & & 1.00 & .12 & -.08 & .06 & $-.37^{* *}$ & .00 \\
\hline 10. Nonresident child support & & & & & & & & & & 1.00 & .20 & .23 & .06 & -.16 \\
\hline 11. Extended family support & & & & & & & & & & & 1.00 & .25 & .19 & $-.40^{* *}$ \\
\hline 12. Neighbor support & & & & & & & & & & & & 1.00 & .04 & $-.40^{* *}$ \\
\hline 13. Social participation & & & & & & & & & & & & & 1.00 & -.23 \\
\hline 14. Depressive score & & & & & & & & & & & & & & 1.00 \\
\hline
\end{tabular}

${ }^{*} p<.05 .{ }^{* *} p<.01$. 
Table 3. Partial Correlations Among Social Support Measures and Depression Score $(N=54)$

\begin{tabular}{lll}
\hline & \multicolumn{2}{c}{ Depressive score } \\
\cline { 2 - 3 } & Phase $1^{a}$ & Phase $2^{b}$ \\
\hline Phase 1 & & \\
Spouse support & -.21 & -.17 \\
Coresident child support & $-.28^{*}$ & -.18 \\
Nonresident child support & $-.29^{*}$ & -.01 \\
Extended family support & $-.34^{*}$ & $-.45^{* *}$ \\
Neighbor support & .05 & -.13 \\
Social participation & -.10 & $-.35^{*}$ \\
Phase 2 & & \\
Spouse support & & -.16 \\
Coresident child support & & -.01 \\
Nonresident child support & & -.07 \\
Extended family support & & $-.34^{*}$ \\
Neighbor support & & $-.45^{* *}$ \\
Social participation & & $-.31^{*}$ \\
\hline
\end{tabular}

${ }^{a}$ Adjusted for age and personal loss.

${ }^{b}$ Ajusted for age, personal loss, and depressive score (phase 1).

${ }^{*} p<.05 .{ }^{* *} p<.01$.

living with participant, child living separately, and extended family were each negatively associated with depressive symptoms: the higher the level of family support, the lower the level of depressive symptoms.

At phase 2, correlations were also adjusted for the phase 1 depressive score. Levels of social support received from extended family and neighbors and social participation were each negatively associated with the level of depressive symptoms. Contrary to the result at phase 1, support received from children was unrelated to the level of depressive symptoms.

\section{Discussion}

On average, depression scores did not change between 6 and 12 months after the earthquake. Although we failed in following up with the nondisplaced group in phase 2 , at phase 1 the depression scores of that group were significantly lower than those of displaced participants. Also, as compared to the previous studies that determined depressive status of older adults by using a similar instrument (Leung et al., 1998; Lu, Liu, \& Yu, 1998), these displaced older adults experienced depressive symptoms for a longer period of time than older adults typically do in Taiwan. Considering these facts, we assumed that the experience of displacement challenged older adults' recovery from disaster-related psychological distress.

According to Parker (1977), relocation after natural disasters may lead to disruption of familiar neighborhood networks and impairment of effective support networks.
Our study revealed that neighbor support increased significantly 6-12 months after the earthquake. We therefore think that it takes a certain time to develop support systems within temporary housing situations.

The benefits of social support varied across time and according to the source of support. In the short term (6-month postearthquake), higher levels of child and extended family support were associated with lower levels of depressive symptoms. In contrast, in the longer term (12-month postearthquake), higher levels of support by extended family and neighbors and social participation were associated with lower levels of depressive symptoms. Antonucci (1985) indicated that the presence of family support does not necessarily have a substantially positive impact, but its absence may be detrimental. Family support plays an important role in regulating and maintaining the standard of living (Kaniasty \& Norris, 1993). Because family support has both instrumental and emotional functions, it would be essential for older adults to receive such support during the acute and early-recovery phases to meet their basic human needs. Family support is routinely observed as a filial obligation to elderly people in Taiwanese culture (Kao \& Stuifbergen, 1999; Shyu, Archbold, \& Imle, 1998). In Taiwan, the older population (65-year old and over) has been rapidly increasing. However, family support systems have been fading out because the family structure has changed under "modernization" (Department of Accounting and Statistics, 1998). Such change makes it more difficult to provide appropriate support to older victims at a community level and became a serious issue after the earthquake.

In contrast, social participation and social support by extended families and neighbors would play a more important role in promoting mental health in later phases of recovery. By these supports, positive thinking and selfesteem are promoted, and victims can eventually attain better psychological status and well-being (Kaniasty \& Norris, 1993). Also, the development of spontaneous support systems within the community, such as social networks of neighborhoods, homeowners' associations, religious groups, and social clubs is considered to empower the elderly and to reduce stress (Eynde \& Veno, 1999). Similarly, an intervention to promote social networks and social participation in the temporary community for the older adults by relief organizations and local authorities is highly recommended so that the displaced older adults can attain better quality of life. In conclusion, although the sample size was not large enough to generalize the results, our longitudinal study suggests that it would be valuable to develop social support systems for older adults who must live in temporary communities following natural disasters. 


\section{Acknowledgments}

The author thanks Prof. Ichiro Kai, Dr Osamu Kunii, and Ms Hu-Shu-Hui for their helpful comments.

\section{References}

Antonucci, T. C. (1985). Personal characteristics, social support and social behavior. In R. H. Binstock \& E. Shanas (Eds.), Handbook of aging and social sciences (2nd ed., pp. 94-128). New York: Van Nostrand Reinhold.

Bland, S. H., O'Leary, E. S., Farinaro, E., Jossa, F., Krogh, V., Violanti, J. M., et al. (1997). Social network disturbances and psychological distress following earthquake evacuation. Journal of Nervous and Mental Disease, 185, 188-194.

Bolin, R., \& Klenow, D. J. (1983). Response of the elderly to disaster: An age-stratified analysis. International Journal of Aging and Human Development, 16, 283-296.

Cohen, S., \& Mckay, G. (1984). Social support, stress and the buffering hypothesis: A theoretical analysis. In A. Baum, J. E. Singer, \& S. E. Taylor (Eds.), Handbook of psychology and health (pp. 253-268). Hillsdale, NJ: Erlbaum.

Department of Accounting and Statistics. (1998). The survey of status of elderly population in Taiwan [Chinese]. Taipei: Ministry of Interior of the Republic of China.

Department of Accounting and Statistics. (2000). The social aid and placement of refugee in 921 big quake analysis [Chinese]. Taipei: Ministry of Interior of the Republic of China.

Eynde, J. D., \& Veno, A. (1999). Coping with disastrous events: An empowerment model of community healing. In R. Gist \& B. Lubin (Eds.), Response to disaster: Psychosocial, community, and ecological approaches (pp. 167-192). Philadelphia: Brunner Mazel.
Gleser, G., Green, B., \& Winget, C. (1981). Prolonged psychosocial effects of disaster: A study of Buffalo Creek. New York: Academic Press.

Kaniasty, K., \& Norris, F. H. (1993). A test of the social deterioration model in the context of natural disaster. Journal of Personality and Social Psychology, 64, 395-408.

Kao, H. F., \& Stuifbergen, A. K. (1999). Family experiences related to the decision to institutionalize an elderly member in Taiwan. Social Science and Medicine, 49, 1115-1123.

Leung, K. K., Lue, B. H., Lee, M. B., \& Tang, L. Y. (1998). Screening of depression in patients with chronic medical diseases in a primary care setting. Family Practice, 15, 67-75.

Lu, C. H., Liu, C. Y., \& Yu, C. Y. (1998). Depressive disorders among the Chinese elderly in a suburban community. Public Health Nursing, $15,196-200$

Noguchi, Y. (1998). Social supports for the elderly people: Concept and measurement [Japanese]. Shakai-Rounengaku, 34, 37-48.

Parker, G. (1977). Cyclone Tracy and Darwin evacuees: On the restoration of the species. British Journal of Psychiatry, 130, 548555 .

Phifer, J. F., \& Norris, F. H. (1989). Psychological symptoms in older adults following natural disaster: Nature, timing, duration, and course. Journal of Gerontology, 44, 207-217.

Raphael, B. (1986). When disaster strikes. How individuals and communities cope with catastrophe. New York: Basic Books.

Shyu, Y. L., Archbold, P. G., \& Imle, M. (1998). Finding a balance point: A process central to understanding family care giving in Taiwanese families. Research in Nursing and Health, 21, 261-270.

Tanida, N. (1996). What happened to elderly people in the great Hanshin earthquake? BMJ, 313, 1133-1135.

Tyler, K., \& Hoyt, D. R. (2000). The effects of an acute stressor on depressive symptoms among older adults: The moderating effects of social support and age. Research on Aging, 22, 143-164.

Zung, W. W. K. (1965). A self-rating depression scale. Archives of General Psychiatry, 12, 63-70. 